\title{
Evolution of Phenolic Composition During Barrel and Bottle Aging
}

\author{
J.L. Aleixandre-Tudo*, W.J. du Toit \\ South African Grape and Wine Research Institute (SAGRWI). Department of Viticulture and Oenology, Stellenbosch University, \\ Private Bag X1, Matieland 7602, South Africa
}

Submitted for publication: June 2020

Accepted for publication: August 2020

Key words: Phenolic compounds, barrel ageing, bottle ageing, anthocyanins, tannins, wine colour, phenolic evolution

\begin{abstract}
During red wine ageing, phenolic compounds undergo several reactions that have an impact on wine colour and mouthfeel properties. The evolution of phenolic content is affected during wine ageing. The aim of this study was to investigate the phenolic content and evolution of 82 commercial red wines subjected to barrel and bottle ageing. The phenolic content evolution of wines that underwent an ageing period of 12 months in commercial 225 litre barrels, followed by 12 months in the bottle, was monitored. While the total phenolic content remained stable, the anthocyanin fraction was affected the most, which led to substantial changes in the colour properties of the wines. Differences were found during both ageing regimes, indicating certain phenolic reactions being favoured or compromised under different ageing conditions, with an impact on wine colour properties. This paper provides the first large-scale study on the phenolic evolution of commercial red wine during ageing.
\end{abstract}

\section{INTRODUCTION}

Phenolic compounds contribute an essential part to the organoleptic attributes of red wines. The roles played by this group of compounds in some of the most important quality attributes of wine lead to an increasing demand for phenolic analysis during winemaking. Among phenolic compounds, two groups, viz. anthocyanins and tannins, are thought to play major roles in wine organoleptic properties (Casassa \& Harbertson, 2014).

The role of anthocyanin is related mainly to the colour properties of wines, and indirectly to the intensity of astringency. The indirect role is due to the decrease in astringency perception derived from tannin-anthocyanin structures (Casassa \& Harbertson, 2014). Anthocyanins initially are found in grapes in monomeric forms; however, due to their reactive nature, a large number of reactions and interactions involving anthocyanins take place during winemaking and ageing (He et al., 2012a).

Proanthocyanidins or tannins have the ability to interact with salivary proteins, leading to macromolecular complexes that evolve until they become insoluble and precipitate from solution, causing a drying sensation known as astringency (Barak \& Kennedy, 2013). The astringency sub-qualities, as well as the bitter taste, are mainly due to tannins differing in composition and conformation. During winemaking, tannincleavage reactions take place together with polymerisation. These reactions, along with tannin insolubility, determine the evolution of the astringency intensity during wine ageing (McRae \& Kennedy, 2011).

Once the fermentation is completed, red wines generally undergo an ageing process. Red wines are commonly exposed to barrel ageing, which lasts from a few months to a few years. Subsequently, red wines often are also aged in bottles for periods of variable duration. During ageing in barrels, red wines are often exposed to increased levels of oxygen, due to its incorporation into the wine matrix through the wood vessel. Some of the reactions between phenolic compounds are promoted by binding agents derived from the oxidation of wine components (Fulcrand et al., 2006; Oliveira et al., 2011). The reactions occurring during this oxidative process are thus different from those occurring in the absence or at low levels of oxygen, i.e. during the bottle-ageing period.

The development of efficient analytical procedures for phenolic analysis, such us the use of spectroscopy calibrations, can contribute to the phenolic information available to scientists and winemakers (Aleixandre-Tudo et al., 2018). On the other hand, the interpretation of the results obtained from current analytical practices is often not understood, and the generated information is therefore not fully utilised. A number of recent research studies have investigated the evolution of phenolic compounds during wine ageing (Sun et al., 2011; Gambuti et al., 2013; Gómez Gallego et al., 2013; Bimpilas et al., 2015). However, these studies normally only report data during bottle ageing, and very often conclusions are made based on the small number of wines made from the same batch of grapes under experimental conditions. Although relevant intrinsic value is provided to the scientific community, an evident gap between the generated knowledge and the commercial/industrial applicability of the results obtained is also observed.

The main aim of this research study was to investigate

*Corresponding author: E-mail address: joaltu@sun.ac.za

Acknowledgements: The authors gratefully acknowledge Winetech South Africa, for financial support under the project (WdT 16/01). 
the evolution of phenolic content and composition of a large number of commercial wines subjected to barrel and bottle ageing through the evaluation of several phenolic and colour parameters. This study might provide a useful contribution to wine producers, potentially extending knowledge of the evolution of phenolic compounds during wine ageing.

\section{MATERIALS AND METHODS}

\section{Reagents}

Hydrochloric acid, sodium metabisulphite, acetaldehyde, tartaric acid and sodium hydroxide were purchased from Sigma-Aldrich Chemie (Steinheim, Germany).

\section{Wine samples}

Eighty-two red wines (2016 vintage) were initially sourced from wineries in the Western Cape region of South Africa after the completion of malolactic fermentation. The sample set included Cabernet Sauvignon (23), Shiraz (19), Pinotage (13), Merlot (11), Ruby Cabernet (2), Cabernet Franc (4), Cinsault (1), Grenache noir (1), Malbec (1), Mourvedre (1), Petit Verdot (4) and Pinot Noir (2), with the number of wines per cultivar shown in brackets. The wines were aged for one year in barrels in an unsupervised approach, i.e. barrels were from different origins, toast intensity and/or number of fills. After barrel ageing, the wines were sampled and bottled under screw cap at the experimental cellar at Stellenbosch University (South Africa), where an additional bottle-ageing period of one year was undertaken under controlled temperature $\left(15^{\circ} \mathrm{C}\right)$. Sulphur dioxide addition was also unsupervised. No instructions were given to the collaborating wineries, and oenological additions were done according to their standard procedures. The wines were therefore analysed after the malolactic fermentation process (T0), as well as after a year of barrel ageing (T1) and after a year of bottle ageing (T2) (two years of ageing in total).

\section{Phenolic analysis}

The modified Somers assay method was used to quantify chemical age 1 and 2, ionised anthocyanins $(\mathrm{mg} / \mathrm{L})$, total anthocyanins $(\mathrm{mg} / \mathrm{L}), \mathrm{SO}_{2}$-resistant pigments and the total phenolic content (Mercurio et al., 2007). Specifically, the colour corresponding to the yellow (420 nm yellow), red (520 nm red) and blue (620 nm blue) wine components was measured, in addition to the total colour intensity (colour density) from the addition of the aforementioned wine colorations (Aleixandre-Tudo et al., 2017). The hue was also calculated as the ratio between the red and yellow wine colours.

\section{Statistical analysis}

Mixed-model ANOVA was used to statistically evaluate significant differences between levels of the phenolic measurements during the ageing period. The unsupervised experimental approach followed in this study caused some of the samples to be lost during the ageing process due to the producers blending the wines. One of the advantages of mixed-model ANOVA applied to longitudinal data is that wines with incomplete data over the ageing process can still be included (Gibbons et al., 2010). Moreover, the existence of significant differences between the change (increase or decrease) taking place during both ageing regimes was also approached statistically. A less conservative Fisher LSD post hoc test at the 0.05 confidence interval was used. Fisher LSD was selected in favour of detecting findings that might be false, rather than missing important results as non-significant. Data analysis was performed with the statistical software package STATISTICA (version 13, TIBCO Software Inc. 2017, http://statistica.io).

\section{RESULTS AND DISCUSSION}

A significant decrease in the total phenolic content (TP) was observed after 12 months of barrel ageing, accompanied by a non-significant decrease between 12 and 24 months of ageing (Table 1). This indicates increased phenolic stability during the bottle-ageing period, with wines being exposed to a less-oxidative environment. Significant differences between the variation in total phenolic content during both ageing regimes were also observed (Table 2), confirming a notable decrease in the total phenolic content during barrel ageing. The majority of the reported studies showed stable total phenolic content during the first few months of ageing, and a slight decrease when wines were evaluated after a few years (Mazza et al., 1999; Darias-Martín et al., 2007; Gambuti et al., 2013; McRae et al., 2013; Rodrigues et al., 2013; Bimpilas et al., 2015). On the contrary, an initial decrease in the total phenolic content, followed by stability over an ageing period of two years, was reported in Tempranillo wines (Revilla \& López, 2005). These latter results, in line with our study, might indicate that the total phenolic content of a young wine is initially altered by oxygen exposure during a certain period, after which the phenolic content becomes less prone to participate in oxidation/degradation reactions.

Monomeric forms of anthocyanins are sensitive to changing $\mathrm{pH}$ conditions, $\mathrm{SO}_{2}$ bleaching and water decolouration (Mercurio et al., 2007; Aleixandre-Tudo et al., 2017). The total anthocyanin content showed significant decreasing levels during the ageing process in our study (Table 1). The results highlight the reactive nature of anthocyanins participating in reactions that span from degradation to self-associations or combinations with other grape and wine components, including other phenolic compounds (He et al., 2012b). The Somers assay measures the simple monomeric anthocyanin forms, which include monomeric anthocyanins and copigmented molecules. The studies reported in the literature showed a steady decrease in the total anthocyanin content during bottle ageing for periods up to 42 months (Kwiatkowski, 2003; Darias-Martín et al., 2007; Gambuti et al., 2013; McRae et al., 2013). Moreover, a study on Tempranillo wines showed notable decreases in the anthocyanin content during the first years of barrel ageing (Revilla \& López, 2005). A slight decrease was observed during the second year, which is in agreement with this study, bearing in mind that our second year of ageing was in bottles (Revilla \& López, 2005). In a similar way as for the total phenolic content, it seems that the magnitude of the anthocyanin reactivity slows down after an initial period in the barrel. However, instead of reaching stability, anthocyanins continue their evolution during the ageing process. 
TABLE 1

Values for average and standard deviation of the phenolic parameters and colour measurements of the wines included in the study. The wines were analysed at the end of fermentation, after 12 months in barrels and after another 12 months in bottles (24 months of total ageing time). Significant differences are shown between the time points. $\mathrm{N}$ corresponds to the number of wines at the time of evaluation.

\begin{tabular}{lccc}
\hline & Time $\mathbf{0}$ months $\mathbf{( N = 8 2 )}$ & Time 12 months $(\mathbf{N}=\mathbf{6 9})$ & Time 24 months $(\mathbf{N}=\mathbf{6 1})$ \\
\hline Total phenolics & $56.54 \pm 12.06 \mathrm{a}$ & $53.41 \pm 9.50 \mathrm{~b}$ & $52.97 \pm 9.61 \mathrm{~b}$ \\
Total anthocyanins $(\mathbf{m g} / \mathbf{L})$ & $471.06 \pm 125.65 \mathrm{a}$ & $336.84 \pm 72.58 \mathrm{~b}$ & $264.12 \pm 61.80 \mathrm{c}$ \\
SO-resistant pigments & $2.78 \pm 0.90 \mathrm{c}$ & $3.25 \pm 0.97 \mathrm{~b}$ & $3.93 \pm 1.21 \mathrm{a}$ \\
Ionisation \% & $22.65 \pm 5.49 \mathrm{~b}$ & $25.17 \pm 5.94 \mathrm{~b}$ & $47.63 \pm 24.94 \mathrm{a}$ \\
Chemical age 1 & $0.33 \pm 0.05 \mathrm{c}$ & $0.47 \pm 0.05 \mathrm{~b}$ & $0.56 \pm 0.06 \mathrm{a}$ \\
Chemical age 2 & $0.12 \pm 0.03 \mathrm{c}$ & $0.19 \pm 0.04 \mathrm{~b}$ & $0.29 \pm 0.08 \mathrm{a}$ \\
$\mathbf{4 2 0}$ nm yellow & $4.98 \pm 1.51 \mathrm{c}$ & $7.26 \pm 2.75 \mathrm{a}$ & $6.51 \pm 1.79 \mathrm{~b}$ \\
$\mathbf{5 2 0}$ nm red & $8.50 \pm 3.37 \mathrm{~b}$ & $10.53 \pm 3.83 \mathrm{a}$ & $9.07 \pm 2.77 \mathrm{~b}$ \\
$\mathbf{6 2 0}$ nm blue & $1.86 \pm 0.69 \mathrm{c}$ & $2.59 \pm 1.05 \mathrm{a}$ & $2.22 \pm 0.70 \mathrm{~b}$ \\
Colour density & $15.35 \pm 5.50 \mathrm{c}$ & $20.38 \pm 7.42 \mathrm{a}$ & $17.80 \pm 5.21 \mathrm{~b}$ \\
Hue & $0.61 \pm 0.09 \mathrm{c}$ & $0.70 \pm 0.12 \mathrm{~b}$ & $0.73 \pm 0.06 \mathrm{a}$ \\
\hline
\end{tabular}

Wines made with Cabernet Sauvignon (23), Shiraz (19), Pinotage (13), Merlot (11), Ruby Cabernet (2), Cabernet Franc (4), Cinsault (1), Grenache noir (1), Malbec (1), Mourvedre (1), Petit Verdot (4) and Pinot Noir grapes (2) were used in the study. The number of wines per cultivar is shown in brackets.

TABLE 2

Increase or decrease between the phenolic levels observed during the barrel and bottle ageing periods. Significant differences between the two periods are reported. $\mathrm{N}$ corresponds to the number of wines at the time of evaluation.

\begin{tabular}{lcc}
\hline & T0-T1 $(\mathbf{N}=\mathbf{6 9})$ & T1-T2 $(\mathbf{N}=\mathbf{6 1})$ \\
\hline Total phenolics index & $3.20 \pm 5.01 \mathrm{a}$ & $0.98 \pm 2.48 \mathrm{~b}$ \\
Total Anthocyanins $(\mathbf{m g} / \mathbf{L})$ & $132.88 \pm 65.06 \mathrm{a}$ & $70.00 \pm 28.12 \mathrm{~b}$ \\
SO2 resistant pigments & $-0.51 \pm 0.41$ & $-0.64 \pm 0.51$ \\
Ionization \% & $-2.41 \pm 7.74 \mathrm{a}$ & $-22.20 \pm 21.17 \mathrm{~b}$ \\
Chemical Age 1 & $-0.14 \pm 0.04 \mathrm{~b}$ & $-0.08 \pm 0.05 \mathrm{a}$ \\
Chemical Age 2 & $-0.07 \pm 0.03 \mathrm{a}$ & $-0.10 \pm 0.06 \mathrm{~b}$ \\
$\mathbf{4 2 0}$ nm yellow & $-2.30 \pm 2.49 \mathrm{~b}$ & $0.90 \pm 2.14 \mathrm{a}$ \\
$\mathbf{5 2 0}$ nm red & $-2.05 \pm 3.65 \mathrm{~b}$ & $1.61 \pm 2.55 \mathrm{a}$ \\
$\mathbf{6 2 0}$ nm blue & $-0.74 \pm 0.94 \mathrm{~b}$ & $0.41 \pm 0.80 \mathrm{a}$ \\
Colour density & $-5.09 \pm 6.83 \mathrm{~b}$ & $2.92 \pm 5.28 \mathrm{a}$ \\
Hue & $-0.09 \pm 0.12 \mathrm{~b}$ & $-0.02 \pm 0.10 \mathrm{a}$ \\
\hline
\end{tabular}

Wines made with Cabernet Sauvignon (23), Shiraz (19), Pinotage (13), Merlot (11), Ruby Cabernet (2), Cabernet Franc (4), Cinsault (1), Grenache noir (1), Malbec (1), Mourvedre (1), Petit Verdot (4), and Pinot Noir grapes (2) were used in the study. The number of wines per cultivar is shown in brackets.

Ionised anthocyanins include those with a positively charged flavilium cation and provide an indication of the monomeric structures responsible for wine colour. A nonsignificant effect in anthocyanin ionisation (\%) during the barrel-ageing period was followed by a significant increase during the bottle-ageing process (Tables 1 and 2). Despite the decrease in the total content of anthocyanins during both ageing periods, the percentage of anthocyanins in the ionised form was at the highest levels at the end of the bottle-ageing period. In agreement with our study, an increase in the ionisation percentage during bottle ageing was reported in Cabernet Sauvignon and Listan Negro wines (Kwiatkowski, 2003; Darias-Martín et al., 2007). However, in contrast to what was observed in this study, the increase in the ionisation 
percentage seemed to be linear during the 24 months' ageing process (Kwiatkowski, 2003). The absence of barrel ageing in the above-mentioned studies limits a direct comparison.

During ageing, simple monomeric forms of anthocyanins lead to an anthocyanin content mostly represented by other, more complex polymeric structures (Waterhouse et al., 2016). It is therefore expected that, in combination with anthocyanin oxidation and degradation, the presence of new pigments, as well as the potential co-precipitation with tannins or other wine components, accounts for the decrease in the monomeric anthocyanin content during wine ageing (Cheynier et al., 2006; He et al., 2012b). The $\mathrm{SO}_{2}$-resistant pigments, ChA1 and $\mathrm{ChA} 2$, parameters that provide the proportion of monomeric to polymeric forms of anthocyanins, are significantly increased during both ageing regimes, as well as during the overall ageing process (Table 1). This may be explained by increased polymeric pigment formation, which includes self-anthocyanin associations, direct and indirect tannin-anthocyanin reactions, pyranoanthocyanin formation or intramolecular copigmented structures (He et al., 2012b; Morata, 2019). Moreover, despite anthocyanin degradation occurring to a larger extent during barrel ageing, the polymeric pigment-formation kinetics were not altered during both ageing regimes (Table 2). Several studies have reported an increase in and steady formation of $\mathrm{SO}_{2}$-resistant pigments during bottle ageing periods of variable duration up to 24 months (Kwiatkowski, 2003; Gambuti et al., 2013; Rodrigues et al., 2013; McRae et al., 2015). Additionally, a decrease in the $\mathrm{SO}_{2}$-resistant pigment levels after three years of bottle ageing has been reported (Bindon et al., 2014), suggesting reversible reactions or net loss of non- bleachable resistant pigments.

A limited number of references were found in the literature reporting on the evolution of the chemical age indexes over time (Kwiatkowski, 2003; Darias-Martín et al., 2007). As expected, both these studies showed an increase in the index during ageing. Differently to what was observed here (Table 2), a linear increase was reported over a 24-month ageing period (Kwiatkowski, 2003). However, the ageing process happened in bottles, restricting a direct comparison with the current study.

Due to the wavelength absorbance nature of some of the phenolic compounds in their simple and also more polymerised forms, colour measurements provide a good indication of the status of phenolic structures in red wines (Kennedy et al., 2006). A significant change in colour was observed during the red wine ageing process, with bluish colourations being turned into more brownish hues (Morata, 2019). Interestingly, the yellow and blue tonalities in our study showed maximum values after the barrel-ageing process, with a subsequent slight decrease observed after bottle ageing (Table 1). Similar results were found for the red colouration; however, no significant differences were found between the initial and final sampling stage. These results are in agreement with a micro-oxygenation study, in which the three colour components increased after a 12-month ageing period (Baiano et al., 2016). On the other hand, the total colour intensity increased significantly when wines were exposed to barrel-ageing conditions, whereas a significant decrease was observed after bottle ageing (Table 1). The exposure to oxygen, in combination with the interactions between the wine and wood phenolic compounds, may explain the observed results (Versari et al., 2013; Gombau et al., 2016). Contradictory results were found in the literature, with studies reporting either an increase or a decrease in colour density during ageing in bottles of variable duration (McRae et al., 2015; Baiano et al., 2016; Gambuti et al., 2017; Petrozziello et al., 2018). However, other studies have reported increases and then decreases in colour intensity in red wines matured in barrels (Revilla \& López, 2005; Laqui-Estaña et al., 2018). Noticeably, and despite the decreased levels of total phenolics observed over time, the new phenolic combinations seem to give rise to phenolic structures with enhanced colouration activity (Du Toit et al., 2006). In addition, a significant increase in the hue was also observed during the ageing period, with a greater increase occurring during barrel ageing compared to bottle ageing (Table 2). This is consistent with what has been reported in the literature. It could be explained not only by oxidation reactions, but also due to formation of some of the polymeric pigments, characterised by increased yelloworange tonalities (pyranoanthocyanins, xanthylium or chalcone forms) (He et al., 2012b; Waterhouse et al., 2016).

\section{CONCLUSIONS}

Stability was observed for the total phenolic content of the wines over the ageing period evaluated. The decrease in phenolics found was mainly due to a decrease in the anthocyanin content. An intense polymeric pigment formation seems to have occurred, affecting the colour properties of the wines. Barrel ageing promotes the intensity of the wine colour, with a subsequent decrease after bottle ageing. Formation of polymeric pigmented structures with enhanced colour properties, but with chemical and oxidative degradation of anthocyanins, is expected to take place during ageing. In addition, cleavage and re-arrangement processes might be the cause of the decrease in colour intensity attributes during bottle ageing. The phenolic chemistry occurring during ageing thus seems to be based on a complex equilibrium involving additional pigment formation and the breakdown and re-arrangement of existing chemical structures. This study shows the importance of considering the ageing regime (barrel or bottle) to better understand the phenolic reactions taking place during wine ageing. However, further studies need to be conducted to fully understand the nature of the reactions, as well as the phenomena taking place in red wines during ageing.

\section{LITERATURE CITED}

Aleixandre-Tudo, J.L., Buica, A., Nieuwoudt, H., Aleixandre, J.L. \& Du Toit, W., 2017. Spectrophotometric analysis of phenolic compounds in grapes and wines. J. Agric. Food Chem. 65(20), 4009-4026.

Aleixandre-Tudo, J.L., Nieuwoudt, H., Olivieri, A., Aleixandre, J.L. \& Du Toit, W., 2018. Phenolic profiling of grapes, fermenting samples and wines using UV-visible spectroscopy with chemometrics. Food Control 85, 11-22.

Baiano, A., De Gianni, A., Mentana, A., Quinto, M., Centonze, D., Alessandro, M. \& Nobile, D., 2016. Colour-related phenolics, volatile composition, and sensory profile of Nero di Troia wines treated with oak chips or by micro-oxygenation. Eur. Food Res. Technol. 242(10), 16311646. 
Barak, J.A. \& Kennedy, J.A., 2013. HPLC retention thermodynamics of grape and wine tannins. J. Agric. Food Chem. 61(18), 4270-4277.

Bimpilas, A., Tsimogiannis, D., Balta-Brouma, K., Lymperopoulou, T. \& Oreopoulou, V., 2015. Evolution of phenolic compounds and metal content of wine during alcoholic fermentation and storage. Food Chem. 178, 164171

Bindon, K.A., McCarthy, M.G. \& Smith, P.A., 2014. Development of wine colour and non-bleachable pigments during the fermentation and ageing of (Vitis vinifera L. cv.) Cabernet Sauvignon wines differing in anthocyanin and tannin concentration. LWT-Food Sci. Technol. 59(2), 923-932.

Casassa, F.L. \& Harbertson, J.F., 2014. Extraction, evolution, and sensory impact of phenolic compounds during red wine maceration. Annu. Rev. Food Sci. Technol. 5(1), 83-109.

Cheynier, V., Dueñas-Paton, M., Salas, E., Maury, C., Souquet, J.M., Sarni-Manchado, P. \& Fulcrand, H., 2006. Structure and properties of wine pigments and tannins. Am. J. Enol. Vitic. 57(3), 298-305.

Darias-Martín, J., Carrillo-López, M., Echavarri-Granado, J.F. \& DíazRomero, C., 2007. The magnitude of copigmentation in the colour of aged red wines made in the Canary Islands. Eur. Food Res. Technol. 224(5), 643648.

Du Toit, W.J., Marais, J., Pretorius, I.S. \& Du Toit, M., 2006. Oxygen in must and wine: A review. S. Afr. J. Enol. Vitic. 27(1), 76-94.

Fulcrand, H., Dueñas, M., Salas, E. \& Cheynier, V., 2006. Phenolic reactions during winemaking and aging. Am. J. Enol. Vitic. 57(3), 289-297.

Gambuti, A., Rinaldi, A., Ugliano, M. \& Moio, L., 2013. Evolution of phenolic compounds and astringency during aging of red wine: Effect of oxygen exposure before and after bottling. J. Agric. Food Chem. 61(8), 1618-1627.

Gambuti, A., Siani, T., Picariello, L., Rinaldi, A., Lisanti, M.T., Ugliano, M., Dieval, J.B. \& Moio, L., 2017. Oxygen exposure of tannins-rich red wines during bottle aging. Influence on phenolics and color, astringency markers and sensory attributes. Eur. Food Res. Technol. 243(4), 669-680.

Gibbons, R.D., Hedeker, D. \& Du Toit, S., 2010. Advances in analysis of longitudinal data. Annu. Rev. Clin. Psychol. 6, 79-107.

Gombau, J., Zamora, F., Vignault, A., Teissedre, P.-L., Pascual, O. \& Canals, J.M., 2016. Influence of supplementation with different oenological tannins on malvidin-3-monoglucoside copigmentation. BIO Web Conf. 7, 02033. EDP Sciences.

Gómez Gallego, M.A., Gómez García-Carpintero, E., Sánchez-Palomo, E., González Viñas, M.A. \& Hermosín-Gutiérrez, I., 2013. Evolution of the phenolic content, chromatic characteristics and sensory properties during bottle storage of red single-cultivar wines from Castilla La Mancha region. Food Res. Int. 51(2), 554-563.

He, F., Liang, N.N., Mu, L., Pan, Q.H., Wang, J., Reeves, M.J. \& Duan, C.Q., 2012a. Anthocyanins and their variation in red wines I. Monomeric anthocyanins and their color expression. Molecules 17(2), 1571-1601.

He, F., Liang, N.N., Mu, L., Pan, Q.H., Wang, J., Reeves, M.J. \& Duan, C.Q., 2012b. Anthocyanins and their variation in red wines II. Anthocyanin derived pigments and their color evolution. Molecules 17(2), 1483-1519.

Kennedy, J.A., Saucier, C. \& Glories, Y., 2006. Grape and wine phenolics: History and perspective. Am. J. Enol. Vitic. 57(3), 239-248.
Kwiatkowski, M.J., 2003. The impact of closures, including screw cap with three different headspace volumes, on the composition, colour and sensory properties of a Cabernet Sauvignon wine during two years' storage. Aust. J Grape Wine R. 13(2), 81-94

Laqui-Estaña, J., López-Solís, R., Peña-Neira, Á., Medel-Marabolí, M. \& Obreque-Selier, E., 2018. Wines in contact with oak wood: The impact of the variety (Carménère and Cabernet Sauvignon), format (barrels, chips and staves), and aging time on the phenolic composition. J. Sci. Food Agric. 99(1), 436-448.

Mazza, G., Fukumoto, L., Delaquis, P., Girard, B. \& Ewert, B., 1999. Anthocyanins, phenolics, and color of Cabernet Franc, Merlot, and Pinot Noir wines from British Columbia. J. Agric. Food Chem. 47(10), 40094017.

McRae, J.M. \& Kennedy, J.A., 2011. Wine and grape tannin interactions with salivary proteins and their impact on astringency: A review of current research. Molecules 16(3), 2348-2364.

McRae, J.M., Day, M.P., Bindon, K.A., Kassara, S., Schmidt, S.A., Schulkin, A., Kolouchova, R. \& Smith, P.A., 2015. Effect of early oxygen exposure on red wine colour and tannins. Tetrahedron 71, 3131-3137.

McRae, J.M., Kassara, S., Kennedy, J.A., Waters, E.J. \& Smith, P.A., 2013. Effect of wine $\mathrm{pH}$ and bottle closure on tannins. J. Agric. Food Chem. 61(47), 11618-11627.

Mercurio, M.D., Dambergs, R.G., Herderich, M.J. \& Smith, P.A., 2007. High throughput analysis of red wine and grape phenolics - Adaptation and validation of methyl cellulose precipitable tannin assay and modified Somers color assay to a rapid 96 well plate format. J. Agric. Food Chem. 55(12), 4651-4657.

Morata, A., 2019. Red wine technology. Academic press, Elsevier, London, UK.

Oliveira, C.M., Ferreira, A.C.S., De Freitas, V. \& Silva, A.M.S., 2011. Oxidation mechanisms occurring in wines. Food Res. Int. 44(5), 1115-1126.

Petrozziello, M., Torchio, F., Piano, F., Giacosa, S. \& Roman, T., 2018. Impact of increasing levels of oxygen consumption on the evolution of color, phenolic, and volatile compounds of Nebbiolo. Front. Chem. 6(6), 137.

Revilla, E. \& López, J.F., 2005. Anthocyanin pattern of Tempranillo wines during ageing in oak barrels and storage in stainless-steel tanks. Eur. Food Res. Technol. 20(5-6), 592-596.

Rodrigues, A., Ricardo-da-silva, J.M., Lucas, C. \& Laureano, O., 2013. Effect of winery yeast lees on Touriga Nacional red wine color and tannin evolution. Am. J Enol. Vitic. 64(1), 98-109.

Sun, B., Neves, A.C., Fernandes, T.A., Fernandes, A.L., Mateus, N., De Freitas, V., Leandro, C. \& Spranger, M.I., 2011. Evolution of phenolic composition of red wine during vinification and storage and its contribution to wine sensory properties and antioxidant activity. J. Agric. Food Chem. 59(12), 6550-6557.

Versari, A., Du Toit, W. \& Parpinello, G.P., 2013. Oenological tannins: A review. Aust. J. Grape Wine Res. 19(1), 1-10.

Waterhouse, A.L., Sacks, G.L. \& Jeffery, D.W., 2016. Understanding wine chemistry. John Wiley and Sons, Chichester, West Sussex, UK. 